\title{
Research into Practice: Cultural and intercultural awareness
}

\section{Will Baker}

University of Southampton, UK

w.baker@soton.ac.uk

Abstract

This article examines the role of cultural awareness (CA) and intercultural awareness (ICA) in classroom theory and practice. CA and ICA can be roughly characterised as an awareness of the role of culture in communication with CA focused on national cultures and ICA on more dynamic and flexible relationships between languages and cultures. There will be a consideration of findings from CA and ICA research that have not been well applied, those that have been well applied and those that have been over applied to classrooms. In particular, it will be argued that CA and ICA are more prevalent in pedagogic theory, and to a lesser extent policy, than they are in practice. While the cultural dimension to language learning is now fairly mainstream, where elements of CA and ICA are applied or translated into the classroom they typically take the form of comparisons between national cultures, often in essentialist forms. There is still little evidence of classroom practice that relates to the fluid ways cultures and languages are related in intercultural communication, especially for English as a lingua franca or other languages used on a global scale.

Will Baker is a lecturer in modern languages and deputy director of the Centre for Global Englishes at the University of Southampton, SO17 1BJ, Hampshire, UK, where he teaches and supervises research in applied linguistics, global Englishes and intercultural communication. He has also taught English in the UK and Thailand. His research interests include intercultural communication, intercultural awareness, English as a lingua franca, ELT and e-learning and he has published and presented internationally in all these areas. 


\section{Introduction}

Culture has long been part of second language (L2) teaching and learning whether through a focus on the literature written in the chosen target language or an interest in the country, people and traditions associated with the language. However, with the socio-cultural turn in applied linguistics, the last few decades have seen an accompanying rise in interest in the cultural dimension to language teaching and learning exemplified in such seminal writings as Kramsch (1993; 1998) and particularly Byram’s (1997) intercultural communicative competence framework. Nonetheless, the influence these and other theoretical and empirical studies have had on teaching practice at the 'chalk-face' is still debatable. In this article I will examine the extent to which research findings have been applied, where this has been done well, where it has not, and where the findings have been over-applied. Such an evaluation will necessarily be subjective, and I will draw on my own experiences of teaching master's level courses in the UK to language teachers from around the world, as well as my experiences of and continued interest in English language teaching (ELT) in Thailand. At the same time though, I will relate these experiences to what we currently understand through research about the role of cultural and intercultural awareness in L2 use and learning. Given my experiences of ELT, the discussion will mainly focus on English language teaching; however, many of the issues will be relevant to teaching other languages.

\subsection{Cultural and intercultural awareness}

The term cultural awareness (CA) has been used by a number of writers in relation to language teaching but its best known formulation is Byram's (1997: 63-64) critical cultural awareness, which forms the core of intercultural communicative competence (ICC). ICC is an attempt to expand the view of communicative competence used in language teaching (i.e. Canale \& Swain 1980) to explicitly recognise the intercultural use to which L2s are put and the range of skills, knowledge and attitudes associated with this. In ICC, rather than 
examining the competence needed for successful 'native speaker' communication, the focus is on communication between participants with different linguaculture backgrounds. Critical cultural awareness is crucial to ICC in providing the foundation for evaluating one's own and other's 'perspectives, practices and products' (Byram 1997: 63). Critical cultural awareness and other formulations of cultural awareness are often presented as a key feature of intercultural competence or as a less technical, more holistic synonym of it (Risager 2004).

More recently the notion of 'intercultural awareness' (ICA) has been put forward (Baker 2011, 2012a) as an approach which builds on CA but takes a more dynamic intercultural perspective. While CA explores the manner in which national conceptions of culture frame intercultural communication, ICA focuses on the INTER or TRANS cultural dimension where there is no clear language- culture- nation correlation, particularly in global uses of English. This also involves a move away from cross-cultural comparisons, where cultures are treated as discrete entities that can be compared with each other, e.g. 'in British culture people do... but in Italian culture people do...'. In contrast an intercultural approach examines communication where cultural differences, at a range of levels, may be relevant to understanding but does not make a priori assumptions about cultural difference. As with CA, awareness in ICA is expanded beyond its everyday usage to include knowledge, skills and attitudes and used as a more holistic alternative to intercultural competence,?? which avoids the problematic competence-performance distinction. Unlike CA, ICA emphasises the flexible and context specific nature of the knowledge, skills and attitudes needed. Recommendations for implementing ICA in the classroom include investigating the relationships between culture, language and communication through: exploring local cultures; exploring language learning materials; exploring the media and arts both online and through more 'traditional' mediums; making use of cultural informants; and engaging in intercultural communication both face to face and electronically (Baker 2012a). This list is not exhaustive 
but rather presents examples of how culture and language can be integrated into ELT classrooms in a non-essentialist manner. A crucial part of each of the areas outlined is that any representations of culture presented are treated critically.

In the rest of this article I will evaluate the degree to which CA and ICA have been applied in teaching practice, particularly in relation to how culture is presented in the classroom and its perceived role in successful L2 communication. This will include discussions of intercultural competence; simple and complex cultural representations and comparisons; recognition of the role of culture in language teaching and how this is integrated with teaching; and the influence of global lingua francas, especially English, on perceptions of intercultural communication in language teaching. The aim is not to provide a comprehensive overview of all research and practice, or theoretical discussions concerning the nature of and relationship between culture and language, but instead to highlight some key pedagogically relevant issues which, I hope, will stimulate further debate.

\section{Research findings that have not been well applied}

\subsection{Intercultural competence}

Successful communication is the result of more than the mastery of a pre-defined set of syntactical, lexical and phonological features and, as might be expected, this has been demonstrated in research from intercultural communication studies (e.g. Spencer-Oatey \& Franklin 2009). Various characterisations of intercultural competence, to which the concepts of CA and ICA are core, share an understanding of intercultural communication as a) knowledge of different communicative practices in different socio-cultural settings; b) the skills to be able to employ this knowledge appropriately and flexibly; and c) attitudes towards communication that involve the ability to de-centre and relativise one's own values, beliefs and expectations. While notions of intercultural competence have rightly been critiqued for, at times, simplifying and essentialising 'other' cultures, people and places (Holliday 2011), 
they still generally take a much wider and more holistic perspective on successful communication than the notions of communicative competence predominantly drawn on in language teaching. Although models of communicative competence have been concerned with socio-cultural appropriateness and communication strategies (e.g. Canale and Swain 1980) this has been critiqued for an unhelpful focus on an idealised native speaker myth (Byram 1997). In language teaching this is frequently restricted to a focus on a bounded 'code' comprising features of syntax, lexis and phonology often associated with this idealised model of a 'native speaker'. Even where the social context and social rules of communication are considered, again this is, as Leung (2005) notes, typically based on a narrow set of 'native speaker' norms derived from the intuitions of teacher trainers or material writers. This provides teachers and learners with a very impoverished picture of what successful communication entails, ignoring many of the insights intercultural communication and sociolinguistic studies have achieved, especially as regards the importance of context, variety, adaptation and change in language and communication.

Research on global uses of language, particularly English as a lingua franca (ELF), English used by interlocutors from different linguacultural backgrounds, provides a good illustration of the fluid and flexible way in which linguistic forms are adapted in response to specific functions, settings and interlocutors (e.g. Jenkins, Cogo \& Dewey 2011; Seidlhofer 2011). The documented uses of English in ELF research are often far removed in form from the models of 'standard native English' presented in teaching materials. This would suggest that competent communicators need to be able to employ linguistic forms in a flexible and reflexive manner rather than adhering to a rigid code. ELF researchers, along with other researchers of intercultural and multilingual communication, have examined a range of communication strategies such as accommodation, code-switching, repetition, explicitness and pre-empting misunderstanding, which facilitate the flexible use of linguistic forms. 
These communicative strategies have been regarded as equally, if not more, important to intercultural communication than knowledge of particular linguistic forms. However, there is little evidence that awareness of such flexible uses of language or the associated communicative strategies form a significant part of language teaching. Yet, without this, L2 learners are likely to be poorly equipped for the linguistic and communicative diversity they will face in intercultural communication. These communicative strategies need to be combined with the other aspects of intercultural competence, particularly those related to ICA, as described above. For example, L2 users need knowledge of other communicative practices and to develop favourable attitudes to highly diverse and potentially demanding communication where their own communicative norms and expectations may be frequently challenged. Finally, and most crucially, a critical and reflexive stance towards such knowledge is needed, as suggested in CA and ICA (see also Kramsch's (2009; 2011) notion of symbolic competence), and the ability to make use of this knowledge in a flexible and context specific manner.

Currently, though, there is little indication of these ideas appearing in L2 teacher training, materials or curricula and the notion of a successful communication is largely based on a restricted view of communicative competence rather than intercultural competence and awareness. Given the increased demands that communicative competence placed on language teachers and classrooms, as well as valid critiques of its relevance in different settings (Kumaravadivelu 2001), it is not surprising that adding further to the range of knowledge and skills expected of language teaching and teachers would meet with resistance (Sercu et al. 2005; Young \& Sachdev 2011). Teachers are, of course, also restricted by externally imposed constraints from curricula and especially testing with large scale testing organisations, such as IELTS and TOEFL, continuing to utilise a monolingual, 'native speaker' and linguistically dominated view of communicative competence. However, 
research into intercultural competence and ICA suggests more flexibility and freedom on the part of language teachers, allowing them to focus on teaching those elements of language and communication which best serve the development of an intercultural competence that is locally relevant, rather than following an externally derived notion of communicative competence. Studies such as those collected in Feng, Byram \& Fleming (2009) show a range of productive and flexible approaches to developing intercultural competence in the classroom and Baker (2012b) demonstrates positive attitudes on the part of teachers to applying ICA in their teaching but at present these are not mainstream approaches. 2.2 Images of culture: simplification vs. complexity Contemporary theories of culture emphasise the complexity, fluidity and multiplicity of cultures with national conceptions of culture forming just one of many cultural groupings individuals identify with (Holliday 2011). Equally we should expect that language learners and teachers may use the L2 to identify with a variety of different cultural groupings, for example those related to professions, generation, or leisure activities. Research such as that conducted by Phan (2008) has shown how English language teachers use English to construct dynamic and changing identities while using their L1 to form more stable identities associated with a particular culture, community and nation. However, language learning materials predominantly focus on a correlation between a language and a particular group of people in a defined geographical national territory. For example, two reviews of representations of culture in text books separated by over 10 years found very similar restricted or essentialist images of cultures (Cortazzi \& Jin 1999; Vettorel 2010). This can lead to overly simplistic and stereotypical understandings of other cultures and people which are more likely to hinder rather than aid intercultural communication and collaboration.

In contrast to this CA, and ICA research in particular, would advocate a more critical approach to culture in which a variety of representation of local, regional, national, and 
transnational cultures are presented in classrooms (Baker 2012a). Crucially, images of culture are approached critically with learners asked to consider why culture is presented in a particular way, what alternative presentations would be possible and the relevance of the images to their own experiences and perceptions (Baker 2012a). In addition, more recent approaches to ICC have also emphasised this critical and political dimension, suggesting that models of language teaching should encourage learners to transcend national-cultural associations and boundaries and aim towards an 'Intercultural', 'Transnational' or 'World' citizenship (Risager 2007; Byram 2008). Such complex and dynamic views of culture may be more challenging for teaching than simplistic stereotypes of other cultures. However, as with revised notions of intercultural competence, they also allow more flexibility and agency for local practitioners. It must also be acknowledged that simplification is a necessary part of teaching (Brumfit 2001) and that at any particularly moment in time some elements of culture must be selected at the exclusion of others. However, it is important to critically review what is and is not selected and to avoid only presenting nation-based views of culture.

In ELT the extensive focus on Anglophone settings such as the US and UK is problematic given the degree to which English functions outside these settings as a lingua franca. Presenting images and materials from other local and regional settings where English is used is more relevant, although, of course, we need to guard against essentialism in these representations too. So for example, in the ASEAN (Association of South East Asian Nations) region, where English is the regional lingua franca, critically exploring various cultures and communities in ASEAN is likely to be of high relevance to English learners (Kirkpatrick 2011). This does not mean exclusion of Anglophone cultures, if they are of interest and relevance to learners, but it does suggest that their relevance to ELT should not be assumed. It would also suggest that where Anglophone cultures are included they need to 
be approached in an equally complex and critical manner rather than simplified stereotypes and 'celebrity snapshots' (Gray 2012).

2.3 The integration of culture into language teaching

Due to the pressures and constraints language teachers face, even when the importance of the cultural and intercultural is recognised in teaching, it typically remains low on a teacher's list of priorities and is rarely systematically integrated into teaching (Sercu et al. 2005; Young \& Sachdev 2011; Driscoll, Earl \& Cable 2013). This is unsurprising given the lack of focus on the intercultural in teacher training, teaching materials, teaching syllabi and language testing. Furthermore, with some notable exceptions (particularly the work of Byram and colleagues, e.g. Byram, Nichols \& Stevens2001), compared to other teaching approaches there has been little empirical research on the 'uptake and perceived applicability of this [intercultural] approach' (Young \& Sachdev 2011: 83). As a result of the scarcity of guidance on 'uptake' and 'applicability' it may not always be clear to teachers how the intercultural should be integrated into teaching. The result of this can be the tacking on of culture as an additional 'fifth skill' to the other four skills (listening, speaking, reading and writing), as suggested by Tomalin (2008) for example. The problems with viewing culture and the intercultural as a 'fifth skill' added on to the other skills as a separate entity have long been noted (e.g. Kramsch 1993). Apart from the obvious implication that as the 'fifth' skill it can be left to last and given the least attention, there is also the problem in viewing culture simply as a skill. As has been discussed here, ICA involves knowledge, attitudes AND skills. Most importantly though, culture is a central part of intercultural communication and intercultural competence and cannot be dealt with in isolation from other aspects of communication.

Where teachers or teaching material attempt to make the intercultural more central in ELT, it is questionable how much this involves recognition of the variation inherent in intercultural communication and the need for a situated emergent understanding of culture 
and language as outlined in ICA. Taking two examples from contemporary ELT texts serves to illustrate this point. 'Global' (Clanfield 2011), as the title suggests, recognises the global role of English and encouragingly emphasises the importance of non-native speakers of English as models in learning the language. Nonetheless, when discussing literature and providing examples of literature written in English, the text still focuses on the Anglophone world rather than looking at texts or literature produced by non-native speakers/writers, missing an important opportunity for more complex socio-cultural contextualisations of English. 'English Unlimited' (Doff 2010), claims in the description to 'focus on intercultural competence as a 'fifth skill'. While the inclusion of intercultural competence as part of the text represents an apparent expansion of communicative competence in a practical setting, its addition as a fifth skill is, as already noted, clearly problematic. Later in the same description it is stated that the CEFR (Common European Framework of Reference) is at the book's core. However, the focus on 'native speaker' norms, expectations and proficiency in the CEFR reveals a concept of communication more in line with earlier restricted understandings of communicative competence. See for example, 'Can sustain relationships with native speakers without unintentionally amusing or irritating them or requiring them to behave other than they would with a native speaker.' (Council of Europe 2001: 122) among the many examples in the CEFR focused on competence related to native speaker communication. It may seem unfair to single out two particular texts in this way and no claims of representation to all ELT materials and teaching can be made. Yet these texts highlight that even when the role of language for intercultural communication and the global nature of communities, cultures and languages are recognised in language teaching, moving beyond traditional (in language teaching at least) perspectives on communicative competence and an association with preestablished language and culture connections remains challenging, with little meaningful in- 
depth engagement with the more complex and fluid view of communication and culture proposed in CA/ICA.

\section{Research findings that have been well applied}

3.1 Recognition of the relationship between culture and language

As stated at the beginning of this paper there has been an increased recognition over the last few decades of the importance of explicitly recognising the close relationship between language and culture in language teaching. This is demonstrated through the large collection of studies examining this relationship in pedagogy from both conceptual and empirical perspectives (for example Valdes 1986; Byram \& Esarte-Sarries 1991; Hinkel 1999; Risager 2007; Feng et al. 2009). Alongside this has been a concern with the place of cultural awareness in language teaching, most notably as already discussed through the work of Byram, but also others (for example Tomalin \& Stempleski 1993; Jones 1995; 2000; Littlewood 2001; Risager 2004; 2007). These approaches have included examining materials or 'realia' from target cultures, making comparisons between this and local equivalents, using cultural topics as discussion points and the content of communication in the classroom, pragmatics and particularly politeness, comparing different communicative practices in different cultures, and reflecting on the role of culture in learners' own identities and communicative practices.

The increased awareness of the role of culture in language learning has also been reflected in language policy as well. For example, in Europe, language policy and most influentially CEFR, makes reference to the intercultural and cultural aspects of language learning including drawing on the work of Byram (e.g. Beacco et al. 2010). Likewise, the 'Standards for foreign language learning in the 21 st ccntury' in the US makes extensive references to culture, the relationship between culture and language and communities (Glisan 2012), as do government reports in other Anglophone settings such as Australia (Scarino 
\&Liddicoat 2009) and New Zealand (Newton et al. 2009) . Taking Thailand as an example from Asia, Wongsatorn, Hiranburana \& Chinnawongs (2003) claim that culture forms one of the four strands of the national curriculum (the others being communication, connections and communities). It is also a requirement that all English language teachers from outside of Thailand familiarise themselves with Thai culture - tested through a formal exam. There are caveats to this, not least that there is frequently a gap between policy and practice. Furthermore, many of the approaches still centre on national and narrow 'native speaker' perspectives on languages and cultures and, as with the materials discussed above, it is not clear that more dynamic intercultural associations between languages, communities and cultures, as envisaged in ICA, are recognised. It is, nonetheless, a sign of how mainstream the notion of culture as part of language teaching has become that such policy documents now expect a degree of cultural awareness from language learners and teachers.

3. 2 Increased awareness of intercultural communication and the diverse global roles of languages

There are some signs that more complex understandings of the relationships between languages, cultures and communication are beginning to emerge in language teaching. In particular there appears to be a growing realisation of the role of English mainly as a global language for intercultural communication, rather than as a language predominantly used in Anglophone settings. Text books produced by mainstream ELT publishers such as 'Global' (Clanfield 2009) are beginning to include a greater variety of Englishes with an associated diversity of cultural associations. Although, as previously discussed, the extent to which this goes beyond surface features is debatable, there seems to be an attempt to incorporate more diverse and multilingual models of English or Englishes into ELT. A number of teacher education text books have gone far beyond surface features. In particular, Walker (2010) offers an approach to teaching pronunciation based on ELF research and crucially emphasizes 
the importance of a range of communicative strategies in effective communication. This more multilingual and multicultural approach to ELT and teacher training and education is reinforced by the appearance of courses in global Englishes and intercultural communication as part of many masters level programmes offered at universities for ELT teachers. At the same time there are an increasing number of text books on intercultural communication which deal with language teaching issues and vice versa, some of which are mentioned here. Additionally, the influential Cambridge ESOL Delta award (Diploma in Teaching English to Speakers of Other Languages) has added World Englishes, Global Englishes, and English as a lingua franca to its syllabus specifications and expects candidates to develop awareness of these subjects, although the degree to which this has influenced the models of language, communication and competence presented is debatable (Dewey 2012).

Recent studies have examined pedagogic applications of a global Englishes perspective that incorporates elements of CA and ICA. Galloway (2013) developed a programme in global Englishes for Japanese university students drawing on a variety of Englishes as well as ELF and the correspondingly diverse socio-cultural contexts in which this communication took place. She also incorporated elements of CA and ICA into the programme. At the end of the programme, students generally expressed positive attitudes towards a variety of Englishes and had developed a better understanding of English in intercultural communication. However, for many of the students, Anglophone varieties of English remained the most prestigious. Baker (2012b) also developed a course in global Englishes and ICA for Thai university students. This course took a perspective that examined local (Thai), regional (Asian) and global uses of English and the diverse sociocultural contexts in which this occurred. It also incorporated elements of ICA, particularly in presenting links between culture and language that were complex and dynamic going beyond national understandings of culture. Again, this research demonstrated the feasibility of such 
an approach and both teachers and students generally reported positive attitudes towards the course. However, as with Galloway's (2013) study, Anglophone varieties of English were still regarded in higher prestige by some students. It was also not clear to what extent students and teachers understood global Englishes as representing many different varieties of English or the varied use of English, as envisaged in ELF research, and the correspondingly fluid relationship between language and culture.

In sum, both studies offer early attempts to present English to language learners in a manner that reflects the diverse uses and forms it takes in intercultural communication and the correspondingly complex and plurilithic socio-cultural associations. While a number of caveats were noted, the generally positive responses from students and teachers would suggest that English courses which adopt the perspective of language, culture and communication presented in ICA are relevant and feasible. Further research is clearly needed though, particularly research that focuses on the language classroom. Indeed, an increasing number of $\mathrm{PhD}$ studies in research centres globally, such as the 'Centre for Global Englishes' at the University of Southampton, are exploring the role of global Englishes, intercultural communication and intercultural awareness in language teaching (see http://www.southampton.ac.uk/cge).

\section{Findings that have been over-applied}

\subsection{Cultural comparisons}

Both ICA and especially CA ???? make use of cultural comparisons to introduce language learners to different cultural practices in relation to communication. Such comparisons are an essential part of gaining knowledge of other cultural practices and of relativizing one's own cultural practices. However, cultural comparisons need to be approached carefully. 
Simplistic images and statements about other cultures which focus solely on national representations of culture, of the type that are found in many language teaching materials, are unlikely to foster ICA and instead are more likely to produce stereotypes. For example, touristic images of Buckingham Palace or the Eiffel Tower do not offer much insight into the cultures of the people who live in these communities and in the case of English are even less relevant to the majority of 'non-native' speakers of the language (see for example the bestselling New Headway (Soars \& Soars 2011) series for such stereotypical images). Similarly unhelpful is taking a cross- cultural approach where generalised statements about how people in a particular culture communicate are compared to generalised statements about another culture for example, the directness of Germans versus the indirectness of the British (again see the New Headway series such as 'A World Guide to Good Manners' (Soars \& Soars 2003: 34)).

These approaches are problematic when applied to understanding individual instances of intercultural communication. Firstly, they focus on comparing cultures at the national level, and neglect other cultural groupings or identifications. Secondly, they are based on a misconception of cultural descriptions as synonymous with individuals in ascribing descriptions of the aggregated communicative practices of a group to the individual. Individuals will always vary considerably more in their behaviour than such emergent, and hence irreducible, culturally based descriptions of communication. Thirdly, cross cultural comparisons assume that people's communicative practices are unchanging. However, in intercultural communication, especially when using a language as a lingua franca, as is often the case with English, interlocutors will typically adapt their behaviour to that of their interlocutor through reciprocal accommodation to enable more effective communication (c.f. Jenkins et al 2011). Lastly, they can obscure power relationships that may be implicit in comparisons that suggest a particular set of communicative practices are more normal and 
'preferred' whereas others are deviant and 'inferior'. Simplistic images of other cultures and cross-cultural comparisons can easily result in essentialist representations of others which hinder rather than aid intercultural communication.

As images and representations of other cultures will necessarily be partial and selective, it is important that they are recognised as such when comparisons are made. This means presenting language learners with a range of different representations of cultures associated with the language, including its L2 users, and exploring these critically as outlined in ICA. Cultural generalisations are, of course, necessary as without such generalised schemata it would be difficult to know where to begin in communication; however, they must be applied very flexibly. While we may begin interactions with unfamiliar interlocutors based on generalisation, perhaps even national ones, it is important that we quickly adapt our communicative practices in situ to our interlocutor rather than staying rigidly to our generalisations about how communication should proceed. Without this flexibility and adaptation, generalisations become stereotypes which impede successful intercultural communication. Such reflexive and adaptable generalisations and comparisons between cultures are still rare in language teaching and have resulted in critiques of the essentialist and othering approaches to the cultural and intercultural (Kramsch 2009; Baker 2011; Holliday 2011).

\section{Conclusion}

As stated at the beginning of this paper, there has been an increased recognition of the significance of culture in L2 learning and use and an awareness of L2 communication as multilingual intercultural communication with distinct features from monolingual or intracultural communication. CA and more recently ICA have been an essential part of this in outlining the types of knowledge, skills and attitudes needed for successful intercultural communication. A range of suggestions for how CA and ICA can be made part of classroom 
practice have been put forward including developing knowledge of other cultures and communicative practices while also being able to critically reflect and adapt this knowledge. Alongside this, recommendations have been made concerning the types of communicative strategies and skills needed for intercultural communication. This intercultural view of L2 learning and teaching has until recently been reflected more in theory and research than in classroom practice. Nonetheless, there is evidence of increasingly diverse views of culture and language and the need for CA and ICA emerging from ELT materials and language policy. However, concerns remain about the danger of essentialism and othering in overly simplistic approaches to dealing with other cultures and intercultural communication. Language teaching needs more emphasis on criticality and reflexivity in approaching the intercultural in a non-essentialist manner but as an ESSENTIAL part of developing ICA and successful communication.

\section{Acknowledgments}

I would like to thank Professor Jennifer Jenkins and Dr Julia Hüttner for initial feedback on this paper as well as the anonymous reviewers and the editor for further insightful comments.

\section{References}

Baker, W. (2011). Intercultural awareness: Modelling an understanding of cultures in intercultural communication through English as a lingua franca. Language and Intercultural Communication 11.3, 197-214.

Baker, W. (2012a). From cultural awareness to intercultural awareness: Culture in ELT. ELT Journal 66.1, 62-70.

Baker, W. (2012b). Using online learning objects to develop intercultural awareness in ELT: A critical examination in a Thai higher education setting. British Council Teacher Development Research Papers. http://www.teachingenglish.org.uk/publications 
Beacco, J.-C., M. Byram, M. Cavalli, D. Coste, M.E. Cuenat, F. Goullier, et al. (2010). Guide for the development and implementation of curricula for plurilingual and intercultural education. Strasbourg: Council of Europe.

Brumfit, C. (2001). Individual freedom in language teaching. Oxford: Oxford University Press.

Byram, M. (1997). Teaching and assessing intercultural communicative competence. Clevedon: Multilingual Matters.

Byram, M., A. Nichols \& D. Stevens (eds.). (2001). Developing intercultural competence in practice. Clevedon: Multilingual Matters.

Byram, M. (2008). From foreign language education to education for intercultural citizenship: Essays and reflections. Clevedon: Multilingual Matters.

Byram, M. \& V. Esarte-Sarries (1991). Investigating cultural studies in foreign language teaching. Clevedon: Multilingual Matters.

Canale, M. \& M. Swain (1980). Theoretical bases of communicative approaches to second language teaching and testing. Applied Linguistics 1.1, 1-47.

Clanfield, L. (2009). Global. Basingstoke: Macmillan.

Cortazzi, M. \& L. Jin (1999). Cultural mirrors: Materials and methods in the EFL classroom. In E. Hinkel (ed.), Culture in second language teaching and learning. Cambridge: Cambridge University Press, 196-219

Council of Europe. (2001). Common European Framework of Reference for Languages : Learning, teaching, assessment. Cambridge: Cambridge University Press.

Dewey, M. (2012). Towards a post-normative approach: Learning the pedagogy of ELF. Journal of English as a Lingua Franca 1.1, 141-170.

Doff, A. (2011). English Unlimited. Cambridge: Cambridge University Press. 
Driscoll, P., J. Earl\& C. Cable (2013). The role and nature of the cultural dimension in primary modern languages. Language, Culture and Curriculum 26.2, 146-160.

Feng, A., M. Byram\& M. Fleming (eds.) (2009). Becoming interculturally competent through education and training. Bristol: Multilingual Matters.

Galloway, N. (2013). Global Englishes and English Language Teaching (ELT) - Bridging the gap between theory and practice in a Japanese context. System 41.3, 786--803.

Glisan, E. (2012). National Standards: Research into practice. Language Teaching 45.4, 515526.

Gray, J. (2012). Neoliberalism, celebrity and 'aspirational content' in English language teaching textbooks for the global market. In D. Block, J. Gray \& M. Holborow (eds.), Neoliberalism and Applied Linguistics. Abingdon: Routledge, 86-113.

Hinkel, E. (ed.) (1999). Culture in second language teaching and learning. Cambridge: Cambridge University Press.

Holliday, A. (2011). Intercultural Communication and Ideology. London: Sage.

Jenkins, J., A. Cogo\& M. Dewey (2011). Review of developments in research into English as a Lingua Franca. Language Teaching 44.3, 281-315.

Jones, B. (1995). Exploring otherness - An approach to cultural awareness. London: CILT.

Jones, B. (2000). Developing cultural awareness. In K. Field (ed.), Issues in modern foreign languages teaching. London: Routledge / Falmer, 158--171.

Kirkpatrick, A. (2011). English as an Asian lingua franca and the multilingualmodel of ELT. Language Teaching 44.2, 212-224.

Kramsch, C. (1993). Context and culture in language teaching. Oxford: Oxford University Press.

Kramsch, C. (1998). Language and culture. Oxford: Oxford University Press.

Kramsch, C. (2009). The multilingual subject. Oxford: Oxford University Press. 
Kramsch, C. (2011). The symbolic dimensions of the intercultural. Language Teaching 44.3, $354-367$.

Kumaravadivelu, B. (2001). Towards a Postmodern Pedagogy. TESOL Quarterly 35.4, 537560.

Leung, C. (2005). Convivial communication: Recontextualizing communicative competence. International Journal of Applied Linguistics 15.2, 121-144.

Littlewood, W. (2001). Cultural awareness and the negotiation of meaning in intercultural communication. Language Awareness 10.2, 189-199.

Mauranen, A. (2012). Exploring ELF: Academic English shaped by non-native speakers. Cambridge: Cambridge University Press.

Newton, J., E. Yates, S. Shearn \& W. Nowitzki (2009). Intercultural Communicative Language Teaching: Implications for Effective Teaching and Learning. Wellington: Ministry of Education.

Phan, L. H. (2008). Teaching English as an international language: Identity, resistance and negotiation. Clevedon: Multilingual Matters.

Risager, K. (2004). Cultural Awareness. In M. Byram (ed.), Routledge Encyclopedia of language teaching and learning. London: Routledge, 159-162.

Risager, K. (2007). Language and culture pedagogy. Clevedon: Multilingual Matters.

Scarino, A. \& A. J. Liddicoat (2009). Teaching and Learning Languages: A Guide. Melbourne: Curriculum Corporation.

Seidlholfer, B. (2011). Understanding English as a Lingua Franca. Oxford: Oxford University Press.

Soars, L.\& J. Soars (2003). New Headway: Intermediate Third Edition: Student's Book. Oxford:Oxford University Press. 
Soars, L.\& J. Soars (2011). New Headway: Elementary Fourth Edition: Student's Book. Oxford: Oxford University Press.

Sercu, L., et al. (2005). Foreign language teachers and intercultural competence : an international investigation. Clevedon: Multilingual Matters.

Spencer-Oatey, H. \& P. Franklin (2009). Intercultural interaction: A multidisciplinary approach to intercultural communication. Basingstoke: Palgrave Macmillan.

Tomalin, B. (2008). Culture - the fifth language skill. Teaching English. http://www.teachingenglish.org.uk/articles/culture-fifth-language-skill

Tomalin, B. \& S. Stempleski (1993). Cultural awareness. Oxford: Oxford University Press.

Valdes, J. M. (1986). Culture bound: Bridging the cultural gap in language teaching. Cambridge: Cambridge University Press.

Vettorel, P. (2010). EIL/ELF and representation of culture in textbooks: Only food, fairs, folklore and facts? In C. Gagliardi \& A. Maley (eds.), EIL, ELF, Global English: Teaching and Learning Issues. Bern: Peter Lang.

Walker, R. (2010). Teaching the pronunciation of English as a Lingua Franca. Oxford: Oxford University Press.

Wongsothorn, A., K. Hiranburana\& S. Chinnawongs (2003). English language teaching In Thailand today. In H.Wah Kam \& R.L.Wong (eds.), English language teaching in East Asia today: Changing policies and practices. Singapore: Eastern Universities Press, 441-453.

Young, T. J., \& I. Sachdev (2011). Intercultural communicative competence: Exploring English language teachers' beliefs and practices. Language Awareness 20.2, 81-98. 